\title{
Teletrabalho na atualidade: quais são os impactos no desempenho profissional, bem-estar e contexto de trabalho?
}

\author{
Karina Pereira Bastos Vilarinho \\ Serviço Federal de Processamento de Dados, Brasília - DF, Brasil \\ Tatiane Paschoal \\ Universidade de Brasília, Brasília - DF, Brasil
}

\section{Gisela Demo}

Universidade de Brasília - Brasília - DF, Brasil

A partir da pandemia imposta pelo novo coronavírus, o teletrabalho mostrou-se uma alternativa de arranjo de trabalho promissora e desejável em tempos de isolamento social, de forma que tem recebido atenção cada vez mais prioritária nas agendas de pesquisas em gestão de pessoas no setor público. O Serviço Federal de Processamento de Dados (Serpro) foi um dos pioneiros na utilização do teletrabalho no Brasil e, portanto, foi escolhido como lócus do estudo. Esta pesquisa levantou os pontos positivos e negativos do teletrabalho no Serpro, sob a ótica de chefes, teletrabalhadores e colegas de teletrabalhadores, e comparou empiricamente usuários e não usuários do teletrabalho quanto ao desempenho profissional, contexto de trabalho e bem-estar no trabalho. Utilizaram-se questionários e conduziram-se a análises textuais, análises de variância e Testes de Mann-Whitney. Entre os pontos positivos do teletrabalho, destacam-se o aumento da produtividade e melhorias na qualidade de vida do teletrabalhador. Entre os pontos negativos, destacam-se dificuldades técnicas e de convívio social. Quanto à comparação, os teletrabalhadores percebem mais positivamente seu contexto de trabalho, seu desempenho profissional e seu bem-estar no trabalho. Este estudo apresenta um diagnóstico que pode prover aos gestores públicos um olhar mais reflexivo no que tange à adoção e subsequente implantação do teletrabalho.

Palavras-chave: arranjos flexíveis de trabalho, home office, teletrabalho 


\section{Teleworking nowadays: what are the impacts on professional performance, well-being and work context?}

From the pandemic imposed by the new coronavirus, teleworking proved to be a promising and desirable work arrangement alternative in times of social isolation, so that it has received increasingly priority attention in human resources management research agendas in the public sector. Federal Data Processing Service (Serpro) was one of the pioneers in adopting teleworking in Brazil and, therefore, it was the locus of this study. This study explored the positive and negative sides of teleworking in Serpro from the point of view of managers, teleworkers and colleagues and also compared teleworkers and no teleworkers with regard to the professional performance, work context and work well-being. The research method included questionnaires and textual analysis, analysis of variance and Mann-Whitney tests. About the positive sides of teleworking, the most relevant points were productivity increase and quality of life increase. About negative sides, technical difficulties and social interaction limitations can be pointed out. Results also showed that teleworkers have more positive perceptions about work context, professional performance and work well-being. This study provides a reflective look on adopting and implementing teleworking for public managers.

Keywords: flexible work arrangements, home office, teleworking

\section{Teletrabajo en la actualidad: ¿cuáles son los impactos en el desempeño profesional, en el bienestar y en el contexto laboral?}

A partir de la pandemia impuesta por el nuevo coronavirus, el teletrabajo demostró ser una alternativa de trabajo prometedora y deseable en tiempos de aislamiento social, por lo que ha recibido una atención cada vez más prioritaria en las agendas de investigación en gestión de personas en el sector público. El Servicio Federal de Procesamiento de Datos (Serpro) fue uno de los pioneros en la adopción del teletrabajo en Brasil y, por lo tanto, fue elegido como el lugar del estudio. Esta investigación exploró puntos positivos y negativos del teletrabajo en Serpro desde el punto de vista de jefes, teletrabajadores y compañeros de trabajo y comparó teletrabajadores y no teletrabajadores en cuanto al desempeño profesional, al contexto laboral y al bienestar laboral. Se utilizaron cuestionarios y se condujeron análisis textuales, análisis de variancia y tests de Mann-Whitney. Sobre los puntos positivos, se destacan el aumento de la productividad y de la calidad de vida. Sobre los puntos negativos, se destacan las dificultades técnicas y las limitaciones en la interacción social. Los teletrabajadores tienen percepciones más positivas del contexto laboral, desempeño profesional y bienestar laboral. El estudio presenta un diagnóstico que puede conceder a los gestores públicos una mirada crítica y reflexiva acerca de la adopción y utilización del teletrabajo.

Palabras-clave: formas flexibles de trabajo, home office, teletrabajo 


\section{Introdução}

A natureza do trabalho humano e o perfil esperado do trabalhador vêm se alterando rapidamente nas últimas duas décadas, acompanhando a introdução e o desenvolvimento de novas tecnologias de produção e gestão. Formas tradicionais de organização do trabalho estão cedendo lugar a modelos e arranjos mais flexíveis, especialmente em tempos de mudanças nas organizações, aceleradas por crises, como a pandemia do novo coronavírus ou Covid-19. É o caso do teletrabalho (Belzunegui; ErRo; PAStor, 2014; CAILlier, 2013; CARNeVAle; HATAK, 2020; KonRAdT; SCHMOOK; MALECKE, 2000).

Essas mudanças e tendências influenciam expectativas e práticas de gestão também na esfera pública, cujas organizações, além de lidarem com demandas por eficiência, transparência, inovação e adaptação comuns às empresas privadas, devem primar por um melhor atendimento ao cidadão, incentivando a cidadania e contribuindo para uma maior credibilidade dos serviços públicos em geral, o que significará uma representação mais efetiva do Estado (DEMO; PEssôA, 2015). Organizações públicas ao redor do mundo têm implantado arranjos flexíveis que modificam os tradicionais locais e horários de trabalho, como forma de alcançar um melhor equilíbrio entre demandas da organização e do trabalhador, além de potencializar o desempenho individual e a efetividade organizacional (Andrade; Oliveira; PANTOja, 2019; CAillier, 2013, Donnelly; Johns, 2020).

Segundo dados divulgados pela Sociedade Brasileira de Teletrabalho e Teleatividades (SOBRATT, 2018), 45\% de uma amostra de empresas pesquisadas já adotavam regularmente o teletrabalho em 2018 e 15\% planejavam implantá-lo. Essa não é uma forma nova de organização do trabalho, e artigos com revisão sistemática de pesquisas sobre seu funcionamento, impactos, pontos positivos e negativos podem ser encontrados desde o início da década de 2000 (KONRADT et al., 2000). Atualmente, já se discutem e se avaliam outros arranjos flexíveis, como o smart working, que não envolve apenas onde se trabalha, mas como e quando se trabalha (MASSIMO, 2017).

Ainda assim, as discussões sobre aplicações e implicações do teletrabalho ganharam novo fôlego no Brasil devido ao cenário de combate à Covid-19. Governantes estaduais publicaram decretos que regulamentam a adoção e o uso do teletrabalho durante a 
pandemia. Por exemplo, o Decreto no 40.546, de 20 de março de 2020, no Distrito Federal; Decreto no 64.648, de 27 de junho de 2017, o qual tornou-se obrigatório para grupos de risco, em março de 2020; e o Decreto 47.006, de 27 de março de 2020, no Rio de Janeiro. Também foram propostas pelo Ministério da Economia novas regras de teletrabalho na administração pública federal. De um dia para o outro, profissionais e organizações dos diferentes setores precisaram adotar o teletrabalho para continuar o atendimento a usuários e clientes. O teletrabalho funciona? O que é necessário para isso? Como afeta desempenho e bem-estar no trabalho? Tais questões foram retomadas tanto no meio acadêmico quanto empresarial.

O presente artigo apresenta um estudo conduzido no Serviço Federal de Processamento de Dados (Serpro) sobre impactos e pontos negativos e positivos do teletrabalho. Cabe salientar que os dados não foram coletados no contexto da pandemia, que tem suas peculiaridades e caracteriza-se como um momento atípico. $\mathrm{O}$ artigo traça uma fotografia do uso do teletrabalho em uma organização pioneira no setor público brasileiro, a adotá-lo de forma abrangente e estruturada.

Nos últimos anos, a tendência à introdução do teletrabalho no setor público brasileiro tem se consolidado por meio de esforços instrumentais e legais, tais como as Portarias no 139/2009 e n 99/2010 do TCU, que autorizam servidores a desempenharem certas atividades fora do órgão ; a recente Resolução n으 227/2015 do Conselho Nacional de Justiça, que disciplina o teletrabalho de servidores no âmbito do Poder Judiciário; a aprovação do Projeto de Lei no $2723 / 15$, que autoriza os órgãos públicos federais a instituir o sistema de trabalho remoto ; e o próprio Sistema Eletrônico de Informações (SEI), um sistema de gestão de processos e documentos eletrônicos.

Muitos são os benefícios do teletrabalho apontados na literatura (BELZUNEGUI; Erro; PAsto, 2014; CAIllier, 2013; Groen et al., 2018; Rocha; Amador, 2018; TAhavori, 2014). Por outro lado, os mesmos estudos revelam possíveis efeitos indesejáveis. As tecnologias de informação e comunicação e os arranjos inovadores de trabalho precisam ser bem usados e compreendidos, de forma que não apenas permitam um aumento de produtividade, mas também não comprometam o bem-estar e o desempenho dos profissionais (SILVA, 2011). 
Foram levantadas as questões: quais são os pontos positivos e negativos do teletrabalho em uma empresa pública com quase três décadas de experiência com o arranjo? Quais são os principais impactos do teletrabalho na referida organização? Tais questões inspiraram os objetivos da presente pesquisa, quais sejam, levantar os pontos positivos e negativos do teletrabalho no Serpro, sob a ótica de chefes, teletrabalhadores e colegas de teletrabalhadores, e comparar usuários e não usuários do teletrabalho no Serpro quanto ao desempenho profissional, contexto de trabalho e bem-estar no trabalho. Trata-se de um estudo de caso único, descritivo e explicativo, que adotou recorte transversal, abordagem qualitativa e quantitativa, além de amostragem que permitiu uma variedade de fonte de dados e a testagem de relações entre as variáveis propostas.

A análise do teletrabalho e seus impactos em atitudes e comportamentos no trabalho nos diferentes contextos organizacionais, incluindo indicadores diversos e múltiplas fontes de informação, consiste em uma lacuna na literatura (ANDRADE; OLIVEIRA; PANTOJA, 2019; KIM; LEE, 2020), aprofundada pela crise socioeconômica trazida pela Covid-19. O presente trabalho contribui para preencher essa lacuna. Ademais, os resultados deste estudo compõem um diagnóstico que pode prover aos gestores públicos um olhar mais reflexivo no que tange à adoção e subsequente implantação do teletrabalho.

\section{Referencial Teórico}

\subsection{Teletrabalho}

Antes de conceituar o teletrabalho, é necessário fazer uma ressalva: arranjos flexíveis de trabalho são diferentes de trabalho flexível ou arranjos de empregos. Esses se configuram como arranjos baseados em forças do mercado para gerenciar os trabalhadores e englobam outros tipos de relações, como subcontratação, trabalho temporário e contratações de grupos de trabalho (CAPPELLI, 1995).

A expressão arranjos flexíveis de trabalho envolve as mudanças organizacionais estratégicas, as quais ganham conotação especial em tempos de crises, que apontam para novas formas de trabalho flexível, sustentadas pelas tecnologias de informação e 
comunicação e por elementos como tempo, local e organização funcional (DoNNELLY; JohnS, 2020; RoSENFIEL; Alves, 2011). O teletrabalho pode ser definido como uma forma de organização de trabalho por meio da qual as atividades podem ser desenvolvidas parcial ou completamente fora do local de trabalho convencional da empresa, com o auxílio de ferramentas e serviços de telecomunicação (KONRADT; SCHMOOK; MALECKE, 2000). Embora seja entendido como nova tecnologia por muitos profissionais e organizações, estudos empíricos sobre o teletrabalho são desenvolvidos desde a década de 1980 (KONRADT; SCHMOOK; MALECKE, 2000).

No contexto do setor privado brasileiro, existe amparo legal para o teletrabalho desde 2011, quando a Lei no 12.551 alterou o artigo 6으 da Consolidação das Leis do Trabalho (CLT) com a determinação de que não pode haver distinção entre o trabalho realizado nas dependências da empresa ou aquele realizado a distância, desde que caracterizada a relação de emprego, tornando iguais tanto o trabalhador interno da empresa quanto o teletrabalhador. Apesar disso, não há uma regulamentação fechada sobre o uso do teletrabalho, o que permite que cada empresa crie seu próprio programa e desenvolva práticas que melhor atendam a suas necessidades e de seus trabalhadores.

Consoante com esses achados, estudos internacionais têm apontado inúmeros benefícios do teletrabalho. Por exemplo, há dados sobre benefícios como usar roupas mais informais para trabalhar, redução do tempo de deslocamento entre casa e trabalho, mais tempo para a família, maior controle sobre o trabalho, ambiente de trabalho mais confortável, melhor organização das tarefas, mais motivação para trabalhar, aumento de produtividade, menos dias de afastamento por motivos de saúde, diminuição de custos com deslocamento e menor distração no desenvolvimento das atividades (TAHAVORI, 2014). Caillier (2013) aponta como benefícios a possibilidade de absorver pessoas portadoras de necessidades especiais ao quadro de colaboradores, a redução da poluição decorrente da melhora no trânsito, a redução de acidentes de trânsito e a redução de custos associados à manutenção de infraestrutura das cidades e das organizações. Belzunegui, Erro e Pastor (2014), por sua vez, apontam benefícios como aumento de autonomia do trabalhador, possibilidade de participação em diferentes projetos, diminuição da necessidade de supervisão constante e enriquecimento de redes de trabalho. 
No contexto brasileiro, pesquisa conduzida no próprio Serpro e na Receita Federal evidenciou vantagens do teletrabalho como a melhoria da qualidade de vida, maior equilíbrio na relação trabalho e família, maior produtividade, flexibilidade, redução de custo e tempo de deslocamento (FILARDI; CASTRO; ZANINI, 2020). Pesquisa com estagiários de uma multinacional revelou vantagens como a relação positiva entre teletrabalho e atividades acadêmicas, a flexibilidade e o amadurecimento profissional como resultado do estabelecimento autônomo de metas individuais de trabalho (ADERALDo, I. L.; AdERALDo, C. V. L.; LIMA, 2017).

Embora benefícios sejam identificados, os estudos também têm sido consistentes em apontar problemas comuns associados à implantação do teletrabalho. Antunes e Braga (2009) já discutiam um lado obscuro da introdução e uso intensivo de novas tecnologias de informação e comunicação. Segundo os referidos autores, embora os novos arranjos de trabalho sejam considerados dinâmicos, as condições de trabalho podem ser tão precárias quanto aquelas existentes no século 19. Infoproletariado ou ciberproletariado foram termos usados para descrever trabalhadores que utilizam tecnologia de ponta, desfrutam de privilégios como uma suposta autonomia, mas vivem sobrecarregados por excesso de trabalho e cobrança, e uma individualização e isolamento excessivo.

Estudos de campo diversos apontam aspectos negativos do teletrabalho, tais como: suporte técnico insuficiente por parte da organização; velocidade de internet e problemas com softwares; problemas com questões de regulamentação legal do teletrabalho; dificuldades de interação e comunicação entre membros do grupo e teletrabalhador; isolamento social do teletrabalhador; sobrecarga de trabalho e falta de tempo de descanso e recuperação, pois os trabalhadores tendem a estender sua jornada quando não há um controle social ou tecnológico dos horários de trabalho (GRANT; WALLACE; SPURGEON; 2013; KonRADT; SCHMOOK; MALECKE, 2000; LEWIS, 2013; TAHAVORI, 2014).

No Brasil, Barros e Silva (2010) destacam a falta de visibilidade do teletrabalhador e a dificuldade relatada por líderes no acompanhamento do desempenho de seus subordinados, retomando questões de controle e avaliação dos teletrabalhadores. A questão do gerenciamento de profissionais que não podem ser vistos todo o tempo foi também levantada por Groen et al. (2018), não exatamente como uma desvantagem, mas como um desafio para os gestores. Filardi, Castro e Zanini (2020) indicam a falta de 
comunicação, perda de vínculo com a empresa, problemas psicológicos, infraestrutura e controle do teletrabalhador. Aderaldo, Aderaldo e Lima (2017) verificaram a sobrecarga de horas de trabalho, a dificuldade de desvincular a vida pessoal do trabalho e os problemas com a visibilidade. Rocha e Amador (2018), por sua vez, ressaltam que existe uma série de riscos envolvidos, principalmente em relação à individualização do trabalho, a qual pode acarretar o isolamento social, profissional e político dos trabalhadores.

Em estudo desenvolvido por Peters et al. (2014), verificou-se que é necessário distinguir entre as práticas oficialmente implementadas na organização e como os empregados as percebem. A simples introdução de novas formas de trabalho pode não alcançar os resultados desejados quando não considera uma cultura organizacional compatível que dê suporte a elas. Lewis (2013) também aponta a importância de questões culturais para a funcionalidade e a efetividade do teletrabalho, argumentando que na cultura francesa, por exemplo, em que as interações e comunicações cara a cara são muito valorizadas, o teletrabalho encontra mais barreiras para se estabelecer.

Com base nos estudos apontados, é possível depreender que o funcionamento e os impactos do teletrabalho não são ponto pacífico e que variáveis organizacionais e pessoais podem ajudar a compreender e discutir o fenômeno. Lewis (2013) ressalta a necessidade de estudar e analisar o teletrabalho a partir de diferentes perspectivas, abordando diferentes tipos de variáveis ou indicadores e captando as percepções dos diferentes envolvidos no processo, como os supervisores de teletrabalhadores, os colegas de teletrabalhadores e os próprios teletrabalhadores. As experiências com os arranjos podem ser distintas, e sua ampla compreensão na organização requer informações das múltiplas fontes.

Portanto, analisar o teletrabalho nos diferentes contextos organizacionais consiste em uma tarefa atual e relevante no campo da gestão, constituindo uma lacuna na literatura. Andrade, Oliveira e Pantoja (2019) verificaram que, apesar da crescente propagação do teletrabalho dentro das instituições públicas, poucos estudos tratam sobre o tema, que carece de aprofundamento nas reflexões teóricas e na testagem de modelos empíricos. Outrossim, Kim e Lee (2020) destacam a necessidade e relevância de evidências empíricas de como programas que visam coordenar demandas pessoais e profissionais, onde se inclui o teletrabalho, afetam atitudes e comportamentos no trabalho. Vale ressaltar 
que as pesquisas sobre teletrabalho costumam focar nos próprios teletrabalhadores ou na comparação de teletrabalhadores e colegas não teletrabalhadores, ignorando as percepções e experiências de chefes e supervisores. Os supervisores no contexto do teletrabalho têm sido um tema amplamente negligenciado (SEEJEEN; CHO, 2020).

A presente pesquisa abordou as percepções de trabalhadores em esquema de teletrabalho, de chefes e de colegas não usuários do teletrabalho, buscando traçar uma visão mais abrangente do fenômeno no Serpro, a partir de múltiplas fontes. Além disso, não se deteve a analisar dados descritivos das percepções sobre vantagens e desvantagens, mas testou empiricamente impactos do teletrabalho em variáveis fundamentais para a efetividade organizacional, a saber, o contexto de trabalho, o bem-estar no trabalho e o desempenho profissional.

\subsection{Contexto de trabalho}

O contexto de trabalho consiste no lócus material, organizacional e social onde se opera a atividade de trabalho (FERREIRA, 2017). Mais especificamente, descreve como as atividades, as tarefas e os papéis são estruturados, desempenhados e modificados, bem como o impacto desses elementos nos resultados organizacionais, grupais e individuais (GRANT; PARKER, 2009).

No presente estudo, foram consideradas as dimensões do contexto referentes à organização do trabalho, às condições de trabalho e às relações socioprofissionais, em função da relevância que têm apresentado em estudos anteriores sobre pontos positivos e negativos e impactos do teletrabalho (AdERALDO; AdERALDO; LIMA, 2017; BARROS; Silva, 2010; Belzunegui; Erro; Pastor, 2014; Caillier, 2013; Filardi; Castro; Zanini, 2020; KonRADT; SCHMOOK; MALECKE, 2000; LEWIS, 2013; TAHAVORI, 2014).

Segundo Ferreira (2017), as condições de trabalho abrangem os equipamentos arquitetônicos, o ambiente físico, os instrumentos, tecnologias e matérias primas presentes na organização. A organização do trabalho envolve elementos como divisão hierárquica, técnica e social do trabalho; metas e objetivos estabelecidos pela organização; natureza, conteúdo, procedimentos e regras para desenvolvimento das tarefas; tempo e processo de trabalho. As relações socioprofissionais abrangem as relações entre chefes e 
subordinados, entre colegas da organização, e entre membros internos da organização e usuários dos serviços/produtos oferecidos pela organização. Foram exploradas possíveis relações do teletrabalho com as condições de trabalho, as relações socioprofissionais e a organização do trabalho, a partir da comparação das percepções de usuários e não usuários do arranjo.

\subsection{Bem-estar no trabalho}

O movimento teórico dos Estudos Organizacionais Positivos tem se destacado como uma corrente de investigação orientada para melhorar as organizações, usando suas forças internas, tendo como pressupostos a saúde e a qualidade de vida, em oposição à doença (CUNHA; REgo; LOPES, 2013).

Nesse contexto, a importância do bem-estar do trabalhador para o funcionamento dos indivíduos e das organizações é consistente na literatura e não se embasa apenas em modelos teóricos, mas em dados de pesquisas de campo (AGAPITO; FILHO; SIQUEIRA, 2015; FogaçA; Coelho JR., 2015; WARR, 2007). Além disso, o bem-estar no trabalho pode ser considerado um indicador da saúde mental nesse importante contexto da vida dos indivíduos (FERREIRA, 2017; WARR, 2007).

Enquanto pesquisas sobre bem-estar geral revelam que variáveis do próprio indivíduo são os principais preditores do fenômeno (CALvo et al., 2015), pesquisas sobre bem-estar no contexto de trabalho revelam que variáveis do trabalho e da organização são os principais antecedentes (Neiva; Macambira; Ribeiro, 2020; PASChoAl; Alvaro; Porto, 2015). O teletrabalho, como arranjo que modifica a organização, as tecnologias e as relações do trabalho, pode ter efeitos diretos e indiretos no bem-estar do trabalhador (GRANT; WALLACE; SPURGEON, 2013), de sorte que compreendê-los é uma tarefa fundamental para uma melhor gestão do arranjo.

Neste estudo, o bem-estar no trabalho é compreendido como a percepção de realização pessoal e os humores e emoções vivenciados no trabalho, de forma que o afeto positivo seja mais frequente e intenso que o afeto negativo (PASCHOAL; TAMAYO, 2008). Embora o conceito de bem-estar no trabalho possa englobar diferentes dimensões cognitivas e afetivas, são os afetos, entendidos como emoções e humores, que consistem 
na sua dimensão central e explicam a maior parte da variância do fenômeno (DEMO; PAschoal, 2016; PAschoal; TAMAYo, 2008; WARR, 2007). Assim, o afeto no trabalho foi utilizado para abordar o bem-estar do trabalhador. Foram exploradas possíveis relações do teletrabalho com o bem-estar no trabalho, a partir da comparação das percepções de usuários e não usuários do arranjo.

\subsection{Desempenho profissional}

Muitas variáveis pessoais, do trabalho e da organização podem influenciar o desempenho de um trabalhador (COElHo JR.; BORges-ANDRAde, 2011; FogAÇA; CoelHo JR., 2015; OlIVEIRA et al. 2019; VREULS; JOIA, 2012). O desempenho pode ser considerado um construto de natureza multideterminada, condicionado a um conjunto de fatores relacionados ao contexto de trabalho, como condições sociais, culturais e relativas ao posto de trabalho do indivíduo (COELHo JR.; BORGES-ANDRADE, 2011).

Na presente pesquisa, o desempenho profissional foi abordado a partir da autoavaliação. Segundo Coelho Jr. et al. (2010), apesar de uma possível parcialidade decorrente da desejabilidade social, medidas de autoavaliação de desempenho podem ser amplamente utilizadas em pesquisas empíricas e apresentam correlações significativas com medidas objetivas de desempenho.

As dimensões que estruturam o desempenho profissional, sob a perspectiva da autoavaliação, são: regulação, ou seja, a avaliação do indivíduo sobre o quanto ele percebe que seu trabalho contribui para o alcance da missão e estratégia da organização; esforço, que consiste na percepção do grau de esforço e ajustamento para alcançar os resultados de trabalho esperados; execução e monitoramento, que abordam o foco no processo de trabalho e desenvolvimento de tarefas e ações; e autogerenciamento, que contempla a eficiência do desempenho, mais especificamente da capacidade de administrar a execução de seu trabalho (COELHO JR. et al., 2010). Foram exploradas possíveis relações do teletrabalho com o desempenho profissional, a partir da comparação das percepções de usuários e não usuários do arranjo. 


\section{Método}

\subsection{Caracterização da pesquisa}

Este artigo apresenta um estudo de caso único, de natureza descritiva e explicativa, que levantou e analisou as percepções de chefes, colegas e teletrabalhadores no Serpro sobre o teletrabalho por meio de questionários com questões abertas e fechadas. O Serpro foi escolhido por ter sido pioneiro no setor público brasileiro a adotar o teletrabalho e por apresentar quase três décadas de iniciativas e mais de uma década de experiência contínua e estruturada com o arranjo.

\subsection{Organização}

No Serpro, o teletrabalho surgiu em 1985 com a implantação do Projeto-Lar, descrito na revista da empresa "Tema" como "primeira experiência em manter um empregado trabalhando em casa, com o apoio de um micro e comunicando-se com a empresa por teleprocessamento" (MAGALHÃES, 1985, p. 23). Naquela época, ainda não havia toda a tecnologia necessária para o teletrabalho, uma vez que, sem a comunicação on-line da máquina do trabalhador com a empresa, todas as informações deveriam ser gravadas em disquetes e levadas à empresa. Assim, o projeto acabou sendo abandonado para voltar a ser repensado em 1997, com o estudo da viabilidade das tecnologias. $\mathrm{Na}$ ocasião, ainda havia uma grande dificuldade no provimento do serviço de internet nas casas dos empregados. O projeto-piloto do teletrabalho foi iniciado efetivamente, então, em 2005.

Com as novas tecnologias, a facilidade cada vez maior da integração da casa e escritório, bem como o retorno positivo das chefias e empregados envolvidos com o projeto, o teletrabalho manteve-se como modalidade de trabalho e estimulou a continuidade do programa, cujo normativo foi revisto em 2012 para abarcar as alterações legais impostas pela Lei no $12.551 / 2011$. As principais características desse programa são a anuência da chefia, o parecer positivo do engenheiro de segurança que atesta a ergonomia do ambiente de trabalho, o compromisso do Serpro no ressarcimento do serviço de bandalarga e o fornecimento do equipamento tecnológico necessário, excetuando-se mobiliário. 
Segundo os dados mais atuais, antes do contexto da pandemia, existiam em torno de 100 teletrabalhadores regulares na empresa.

\subsection{Amostra e instrumentos}

O público-alvo do estudo englobou os atuais empregados cadastrados na modalidade teletrabalho, suas chefias respectivas e os colegas diretos desses teletrabalhadores. Como colegas, foram considerados aqueles que exerciam as mesmas atividades que os teletrabalhadores, que trabalhavam diretamente com eles, mas não utilizavam o teletrabalho. Além dos teletrabalhadores, foram compostas amostras de colegas e de chefes de teletrabalhadores, que desenvolvem suas atividades presencialmente nas dependências do Serpro, já antecipando que a taxa de retorno aos instrumentos aplicados não seria de $100 \%$. As atividades de trabalho são variadas, como desenvolvimento de sistemas, comunicação social e atividades da universidade corporativa do Serpro.

Dos 102 questionários enviados aos teletrabalhadores, 45 foram devolvidos respondidos. Em relação aos colegas, dos 204 enviados, 62 foram devolvidos. Quanto aos chefes, dos 48 enviados, retornaram 23 questionários respondidos.

Do total de respondentes, 65 eram homens. Em relação ao tempo de serviço, 60 empregados tinham de 21 a 40 anos de empresa; apenas 17 empregados tinham até cinco anos de empresa. Quanto à idade, 51 respondentes tinham entre 51 e 60 anos, entre eles 25 teletrabalhadores. Ainda sobre a idade, seis pessoas indicaram ter mais de 60 anos, quatro deles teletrabalhadores. Os respondentes de todos os grupos, portanto, são pessoas com considerável experiência profissional e conhecimento da organização.

Para a coleta de dados, foram utilizadas questões abertas elaboradas para este estudo e medidas já validadas de bem-estar no trabalho (DEMO; PASCHOAL, 2016; PASChoal; TAMAYo, 2008), desempenho no trabalho (Coelho JR. et al., 2010) e contexto de trabalho (FERREIRA, 2011). Para responder ao primeiro objetivo, que consistia em comparar percepções de chefes, colegas e teletrabalhadores quanto a pontos positivos e negativos do teletrabalho no Serpro, foram propostas as seguintes questões abertas: 1) na sua opinião, quais são os pontos fortes associados ao teletrabalho no Serpro?; 2) na sua opinião, quais são os pontos fracos associados ao teletrabalho no Serpro? Todos os participantes deveriam responder. 
Para atender ao segundo objetivo, ou seja, comparar percepções de teletrabalhadores e colegas de teletrabalhadores, foram aplicadas as medidas anteriormente mencionadas aos teletrabalhadores e aos colegas de teletrabalhadores. Da escala de bem-estar no trabalho, foram utilizados os 9 itens de afeto positivo, como alegre e tranquilo, e os 12 itens de afeto negativo, como irritado e deprimido. A escala de resposta variava de 1 (nem um pouco) a 10 (extremamente), com a instrução "nos últimos seis meses, meu trabalho tem me deixado...". A medida de desempenho profissional foi composta por 29 itens, como "meu trabalho é importante para o desempenho do Serpro" e "posso executar meu trabalho sem pressão", distribuídos nos fatores de regulação, esforço, execução/monitoramento e autogerenciamento, e que deveriam ser respondidos de acordo com uma escala de 10 pontos ( $1=$ discordo totalmente e $10=$ concordo totalmente). Por fim, a medida de contexto continha 13 itens, como "divisão das tarefas é justa", "posso trabalhar sem pressão" e "há confiança entre os colegas", distribuídos nos fatores de condições de trabalho, organização do trabalho e relações socioprofissionais. A escala de resposta era a mesma da medida de desempenho. Os índices de confiabilidade das medidas variam de 0,60 a 0,93.

\subsection{Procedimentos de coleta e análise dos dados}

Os questionários foram disponibilizados em ambiente virtual do Google Drive, cujo link foi encaminhado através de e-mail corporativo para todos aqueles que se enquadravam no perfil de respondente.

Em relação às questões abertas, utilizou-se o software Iramuteq, que permite identificar as informações essenciais dos textos e, a partir da quantificação das frequências, acessar as estruturas significantes mais fortes do material (CAMARGO; JUSTO, 2013). Conforme os autores, realizou-se a categorização das respostas por meio da classificação hierárquica descendente (CHD), que propõe a classificação dos segmentos de texto em função de seus respectivos vocabulários. Cada classe identificada apresenta vocabulários semelhantes entre si e diferentes dos segmentos de texto das outras classes (CAMARGO; JUSTO, 2013). Quanto às questões fechadas, primeiramente foram conduzidas análises estatísticas descritivas. Para comparação dos grupos (teletrabalhadores e colegas), foram conduzidas análises de variância e Testes de Mann-Whitney. 


\section{Análise e discussão dos resultados}

O Quadro 1 apresenta os resultados sobre os pontos negativos do teletrabalho no Serpro, de acordo com as chefias. Na primeira coluna, encontram-se as classes temáticas e o quanto elas representam do discurso. Observa-se que as dificuldades técnicas foram as protagonistas dos pontos negativos levantados pelas chefias. É importante notar que a porcentagem expressa não é de respondentes que mencionaram o conteúdo, mas o quanto a referida classe representa de todo o discurso produzido. Na segunda coluna, encontram-se exemplos de falas dos respondentes, que ilustram e detalham o conteúdo da classe.

\section{Quadro 1 | Pontos negativos do teletrabalho sob a ótica das chefias}

\begin{tabular}{|l|l|}
\hline $\begin{array}{l}\text { Classe temática } \\
\text { (\% representatividade) }\end{array}$ & Exemplos de falas dos respondentes \\
\hline $\begin{array}{l}\text { Dificuldades técnicas } \\
(35,90 \%)\end{array}$ & $\begin{array}{l}\text { "...muitas vezes o firewall bloqueia o acesso ao trabalho } \\
\text { "aplicação", gerando desgaste muito grande e stress ainda } \\
\text { maior para liberar o acesso... está prejudicando a execução dos } \\
\text { trabalhos." } \\
\text { “....acesso do empregado a determinados sistemas que são } \\
\text { bloqueados, o trâmite de liberação é moroso e muitas vezes } \\
\text { termina no limbo, não é atendido." }\end{array}$ \\
\hline $\begin{array}{l}\text { Dificuldade de interação com a a } \\
\text { equipe } \\
(18,90 \%)\end{array}$ & $\begin{array}{l}\text { "...diminuição da visibilidade perante o restante da equipe, } \\
\text { dependência de ferramentas e tecnologias diferentes da } \\
\text { estação de trabalho comum." } \\
\text { "...perda das conversas entre a equipe onde algumas } \\
\text { informações são divulgadas" }\end{array}$ \\
\hline $\begin{array}{l}\text { Acompanhamento de novos } \\
\text { usuários } \\
(15,10 \%)\end{array}$ & $\begin{array}{l}\text { "...falta de acompanhamento sistemático acerca da adaptação } \\
\text { do empregado e chefias; para mudanças de maior impacto nas } \\
\text { equipes, temos utilizado um acompanhamento por parte do } \\
\text { serviço social." }\end{array}$ \\
\hline $\begin{array}{l}\text { Sugestões de melhoria } \\
(15,10 \%)\end{array}$ & $\begin{array}{l}\text { "...oportunidade para melhorias, flexibilização horário, medição } \\
\text { por resultados." } \\
\text { "Serpro pode investir mais na seleção." } \\
\text { "Melhor suporte tecnológico para acompanhamento do horário } \\
\text { trabalhado." }\end{array}$ \\
\hline
\end{tabular}




\begin{tabular}{|l|l|}
\hline $\begin{array}{l}\text { Classe temática } \\
\text { (\% representatividade) }\end{array}$ & Exemplos de falas dos respondentes \\
\hline $\begin{array}{l}\text { Dificuldades de gestão } \\
(15,10 \%)\end{array}$ & $\begin{array}{l}\text { “...adaptação da gestão frente à quebra de paradigma do } \\
\text { teletrabalho, carência de meios de comunicação mais interativos } \\
\text { que possibilitem videoconferências para reuniões imediatas } \\
\text { com teletrabalhador e equipe presencial, teletrabalho é uma } \\
\text { proposta mais flexível, porém segue as mesmas regras do } \\
\text { trabalho presencial." } \\
\text { "impossibilidade de registro de ponto dificulta a gestão da } \\
\text { jornada de trabalho do empregado, por limitações de acesso } \\
\text { remoto a algumas ferramentas, o teletrabalhador da área de } \\
\text { produção não utiliza toda a sua potencialidade" }\end{array}$ \\
\hline
\end{tabular}

Fonte: elaborado pelas autoras.

O Quadro 2 apresenta os pontos negativos do teletrabalho no Serpro, segundo os colegas dos teletrabalhadores. O conteúdo se organizou em torno de seis categorias, com a questão do convívio com colegas representando a maior fatia do discurso.

\section{Quadro 2 | Pontos negativos do teletrabalho sob a ótica dos colegas (pares)}

\begin{tabular}{|c|c|}
\hline $\begin{array}{l}\text { Classe temática } \\
\text { (\% representatividade) }\end{array}$ & Exemplos de falas dos respondentes \\
\hline $\begin{array}{l}\text { Convívio com os colegas } \\
(29,60 \%)\end{array}$ & $\begin{array}{l}\text { "...falta de humanidade, isto é, convivência diária entre as } \\
\text { pessoas." } \\
\text { "...distancia-se dos verdadeiros colegas." }\end{array}$ \\
\hline $\begin{array}{l}\text { Exclusão } \\
\text { teletrabalhadores } \\
(17,30 \%)\end{array}$ & $\begin{array}{l}\text { "...muitas vezes esses funcionários são esquecidos para } \\
\text { participação em trabalhos que envolvem reuniões presenciais e } \\
\text { sua participação por audioconferência é, muitas vezes, precária." } \\
\text { "...devido à nossa cultura se perde a identidade funcional, uma } \\
\text { vez que os teletrabalhadores não são vistos com frequência na } \\
\text { empresa e vão sendo esquecidos devido ao não contato visual e } \\
\text { diário." }\end{array}$ \\
\hline $\begin{array}{l}\text { Interferência família- } \\
\text { trabalho e prejuízos para o } \\
\text { desenvolvimento profissional } \\
(16,10 \%)\end{array}$ & $\begin{array}{l}\text { "...as atividades cotidianas da residência do teletrabalhador } \\
\text { podem influenciar de forma negativa a concentração deste" } \\
\text { "...não separação da vida profissional da vida pessoal, menos } \\
\text { oportunidades de promoção e ascensão na carreira profissional, } \\
\text { aumentos de custos com equipes e telecomunicações." }\end{array}$ \\
\hline $\begin{array}{l}\text { Sem pontos negativos } \\
(12,30 \%)\end{array}$ & “...não identifico pontos fracos" \\
\hline
\end{tabular}




\section{Classe temática}

(\% representatividade)

\section{Exemplos de falas dos respondentes}

“... teria que ir para a empresa exclusivamente para bater o ponto

Dificuldade de comunicação e tentar conseguir uma sala de reunião para ficar lá sozinha, imediata com a equipe $(12,30 \%)$ ligando para minha equipe, que está em outros estados." “...atrapalha o tratamento de situações imprevistas em função da limitação de canais imediatos de comunicação."

“...benefício não é concedido baseado no fator distância, que é o fator mais importante, não existindo um critério claro que identifique por que um funcionário recebe o benefício e outro não."

Fonte: elaborado pelas autoras.

O Quadro 3 apresenta os resultados sobre os pontos negativos do teletrabalho no Serpro, sob a ótica os teletrabalhadores. Preconceito, desconfiança e dificuldades técnicas representaram as maiores fatias do discurso.

\section{Quadro 3 | pontos negativos do teletrabalho sob a ótica dos teletrabalhadores}

\begin{tabular}{|l|l|}
\hline $\begin{array}{l}\text { Classe temática } \\
\text { (\% representatividade) }\end{array}$ & Exemplos de falas dos respondentes \\
\hline $\begin{array}{l}\text { Preconceito e desconfiança } \\
\text { de chefes e colegas } \\
(21,70 \%)\end{array}$ & $\begin{array}{l}\text { "...chefias que ligam de tempos em tempos para verificar se a } \\
\text { pessoa está no ambiente do trabalho sem qualquer assunto, } \\
\text { deveria existir uma campanha mais acirrada da empresa sobre o } \\
\text { que é e o que fazem as pessoas em contrato de teletrabalho." } \\
\text { "...preconceito de alguns com relação aos teletrabalhadores, } \\
\text { ex: você está trabalhando? você está fisicamente na regional do } \\
\text { Serpro?" }\end{array}$ \\
\hline $\begin{array}{l}\text { Dificuldades técnicas } \\
(21,70 \%)\end{array}$ & $\begin{array}{l}\text { "...rede não suporta os aplicativos software livre, impede uma } \\
\text { impressão adequada, ramal passa a maior parte do tempo sem } \\
\text { acesso." } \\
\text { "...não consigo utilizar o recurso de compartilhamento de tela, } \\
\text { acesso restrito a algumas aplicações intranet, qualidade da } \\
\text { telefonia IP ainda é deficiente." } \\
\text { "...há alguns problemas de software e hardware que } \\
\text { encontramos sempre, dificuldade de pessoas para resolver } \\
\text { imediatamente, não temos uma pessoa específica a recorrer, } \\
\text { quando há algum problema, sempre ficam empurrando para } \\
\text { outra área e demora." }\end{array}$ \\
\hline $\begin{array}{l}\text { Convívio com os colegas } \\
(19,30 \%)\end{array}$ & $\begin{array}{l}\text { "...perda da convivência diária com colegas, perda de algumas } \\
\text { informações e detalhes que são repassadas oralmente ao grupo." } \\
\text { "...distanciamento no convívio com colegas de trabalho." }\end{array}$ \\
\hline
\end{tabular}




\begin{tabular}{|l|l|}
\hline $\begin{array}{l}\text { Classe temática } \\
\text { (\% representatividade) }\end{array}$ & Exemplos de falas dos respondentes \\
\hline $\begin{array}{l}\text { Dificuldades de gestão } \\
(19,30 \%)\end{array}$ & $\begin{array}{l}\text { “...o principal é a falta de liberação de acesso a alguns sistemas } \\
\text { por questões de políticas de segurança que não fazem sentido, } \\
\text { razões aparentemente mais subjetivas do que técnicas.” } \\
\text { “...trabalho não é por resultado e sim por carga horária, não } \\
\text { permite a compensação de horas.” }\end{array}$ \\
\hline $\begin{array}{l}\text { Apoio da empresa } \\
(18,10 \%)\end{array}$ & $\begin{array}{l}\text { “...pouco apoio da empresa, falta de melhores mecanismos de } \\
\text { comunicação." }\end{array}$ \\
\hline
\end{tabular}

Fonte: elaborado pelas autoras.

E quais são os pontos positivos do teletrabalho no Serpro, a partir da percepção dos diferentes atores organizacionais? O Quadro 4 descreve os pontos positivos, segundo as chefias, e a melhoria na qualidade de vida desponta como a classe mais representativa do discurso.

\section{Quadro 4 | pontos positivos do teletrabalho sob a ótica das chefias}

\begin{tabular}{|c|c|}
\hline $\begin{array}{l}\text { Classe temática } \\
\text { (\% representatividade) }\end{array}$ & Exemplos de falas dos respondentes \\
\hline $\begin{array}{l}\text { Melhoria na qualidade de } \\
\text { vida } \\
(59,20 \%)\end{array}$ & $\begin{array}{l}\text { "...promoção da qualidade de vida do trabalhador, diminuição das } \\
\text { despesas, do desgaste físico e psicológico com os deslocamentos, } \\
\text { aumento do tempo disponível para dedicação a atividades } \\
\text { pessoais." } \\
\text { "...maior satisfação do empregado, motivação em função da } \\
\text { distância casa x trabalho, no teletrabalho há melhor gestão do } \\
\text { horário de trabalho, os resultados são entregues com maior } \\
\text { qualidade, há menor interferência externa na execução das } \\
\text { demandas." } \\
\text { "melhoria da qualidade de vida de uma forma geral, diminuição } \\
\text { do stress do trânsito, do deslocamento ao trabalho, aumento do } \\
\text { foco no trabalho, pois em casa conseguimos isolar o ambiente } \\
\text { de trabalho de conversas paralelas, ruídos e outras situações que } \\
\text { atrapalham sua concentração .." } \\
\text { "....qualidade de vida e bem-estar, além de economia e o } \\
\text { resultado positivo para a nossa organização." }\end{array}$ \\
\hline $\begin{array}{l}\text { Flexibilidade } \\
(25,40 \%)\end{array}$ & $\begin{array}{l}\text { "...flexibilidade e conforto" } \\
\text { "...maior flexibilidade de trabalho, maior foco no resultado." }\end{array}$ \\
\hline
\end{tabular}




\section{Classe temática}

(\% representatividade) subordinados

$(15,20 \%)$

\section{Exemplos de falas dos respondentes}

“...retenção de talentos e experiências na empresa, autonomia das chefias imediatas no deferimento da solicitação do empregado..."

"... desoneração dos controles ortodoxos de acompanhamento das atividades, o nível de relacionamento transcende o modelo chefia $x$ subordinado, alcançando um estado de comprometimento, cumplicidade entre os envolvidos..."

Fonte: elaborado pelas autoras.

O Quadro 5 apresenta os resultados sobre os pontos positivos do teletrabalho no Serpro, sob a ótica os colegas. A facilidade de deslocamento e a economia com gastos pessoais despontaram com a maior fatia do discurso.

\section{Quadro 5 | Pontos positivos do teletrabalho sob a ótica dos colegas (pares)}

\section{Classe temática}

(\% representatividade)

Facilidade de deslocamento e economia com gastos pessoais $(35,40 \%)$

\section{Exemplos de falas dos respondentes}

“...principalmente nas grandes metrópoles, o empregado gasta tempo demais para seus trajetos entre casa $x$ trabalho, 0 que resulta num stress do trânsito e prejudica o desempenho profissional..."

"...economia com despesas com transportes em geral e com vestuário e alimentação, a possibilidade de não ter stress do trânsito e perda de tempo com o deslocamento."

“...economia de tempo, saúde e dinheiro ao evitar o deslocamento em cidades grandes, cada vez mais complexas, perigosas e lotadas."

“...flexibilidade de horário de trabalho para tarefas que podem ser

Condições e organização do trabalho

$(25,30 \%)$ executadas de forma individual, é quando estamos mais relaxados em casa que temos boas ideias que afetam nosso trabalho." "...uma melhor organização das atividades a serem executadas, torna quase que obrigatória a gestão por resultados e não por horário."

“...favorece o empregado em relação à qualidade de vida." Melhoria na qualidade de vida $(24,10 \%)$
"... maior qualidade de vida, mais conforto por estar em casa, mais disponibilidade para a equipe, mais produtividade porque o empregado está mais descansado, possibilidade de poder se mudar para outras cidades, por exemplo cidades menores e mais calmas, não necessitando morar em uma capital." 


\begin{tabular}{|l|l|}
\hline $\begin{array}{l}\text { Classe temática } \\
\text { (\% representatividade) }\end{array}$ & Exemplos de falas dos respondentes \\
\hline & $\begin{array}{l}\text { "...economia para a empresa, melhor distribuição de espaço físico, } \\
\text { melhor produtividade, funcionário se sente motivado." } \\
\text { "...redução dos níveis de hierarquia intermediária, possibilitando } \\
\text { aconomia para a empresa } \\
\text { (15,20\%) }\end{array}$ \\
$\begin{array}{l}\text { vantagens de localização, trabalho em tempo real com pessoas de } \\
\text { qualquer parte do mundo, possibilidade de contratação de mão } \\
\text { de obra mais barata." }\end{array}$ \\
\hline
\end{tabular}

Fonte: elaborado pelas autoras.

Por fim, o Quadro 6 apresenta os resultados sobre os pontos positivos do teletrabalho no Serpro, na visão dos próprios teletrabalhadores. Apenas três classes equilibraram o conteúdo das respostas, com destaque para o aumento da produtividade.

\section{Quadro 6 | Pontos positivos do teletrabalho sob a ótica dos teletrabalhadores}

\begin{tabular}{|c|c|}
\hline $\begin{array}{l}\text { Classe temática } \\
\text { (\% representatividade) }\end{array}$ & Exemplos de falas dos respondentes \\
\hline $\begin{array}{l}\text { Aumento da p } \\
\text { rodutividade } \\
(34,40 \%)\end{array}$ & $\begin{array}{l}\text { "...último relatório de produtividade que me foi enviado teve } \\
\text { números impressionantes, pois acabei sendo responsável por } \\
50 \% \text { da produtividade da nossa área." } \\
\text { "...mais foco nas minhas atividades, de forma a ter um } \\
\text { desempenho melhor e com melhor qualidade mesmo com } \\
\text { alguma doença que possivelmente ficaria em casa, posso } \\
\text { trabalhar e realizar minhas tarefas diárias." } \\
\text { "...aumentou minha motivação em realizar as atividades, } \\
\text { melhorou minha produtividade, não necessito me deslocar para } \\
\text { enfrentar um tr ânsito lento e congestionado, evito as más } \\
\text { condições climatéricas, tenho mais segurança evitando assaltos." }\end{array}$ \\
\hline $\begin{array}{l}\text { Melhoria na qualidade } \\
\text { de vida e facilidade de } \\
\text { deslocamento } \\
(32,80 \%)\end{array}$ & $\begin{array}{l}\text { "...eliminação do stress do trânsito, aumento da qualidade de } \\
\text { vida, maior tempo para a família." } \\
\text { "...aumento da produtividade individual, eliminação de stress } \\
\text { do trânsito, tranquilidade e zero ruído, o que me permite } \\
\text { concentração total no trabalho, melhora na qualidade de vida, } \\
\text { pois o tempo que perdia em deslocamento tenho utilizado para } \\
\text { praticar exercícios, caminhada." } \\
\text { "...ganho do tempo gasto no deslocamento para a empresa, fim } \\
\text { do stress do trânsito, provocando atraso no cumprimento do } \\
\text { horário, aumento da qualidade de vida." }\end{array}$ \\
\hline
\end{tabular}




\begin{tabular}{|l|l|}
\hline $\begin{array}{l}\text { Classe temática } \\
\text { (\% representatividade) }\end{array}$ & Exemplos de falas dos respondentes \\
\hline $\begin{array}{l}\text { Condições e o rganização } \\
\text { do trabalho } \\
(32,80 \%)\end{array}$ & $\begin{array}{l}\text { “...consigo administrar muito melhor meu tempo." } \\
\text { harmonibilidade de realização de tarefas em ambiente } \\
\text { "...conforto, podequado..." } \\
\text { "...possibilidade de executar as tarefas no tempo e no prazo } \\
\text { acordado, com uma maior tranquilidade, a concentração é } \\
\text { melhor nessas condições de trabalho." }\end{array}$ \\
\hline
\end{tabular}

Fonte: elaborado pelas autoras.

Quanto à comparação de teletrabalhadores e colegas em relação ao contexto de trabalho, desempenho profissional e bem-estar no trabalho, alguns cuidados foram tomados antes das análises propriamente ditas. Após a exclusão dos sete outliers univariados e multivariados encontrados, foi obtido um total de 56 respondentes teletrabalhadores e 45 respondentes não teletrabalhadores. Inicialmente, como os grupos de teletrabalhadores e colegas tinham tamanhos equilibrados, todas as variáveis seriam submetidas a testes paramétricos. Contudo, para as variáveis condições de trabalho, regulação e afeto negativo, o teste Levene e o teste KolmogorovSmirnov indicaram não haver normalidade e igualdade de variância entre os grupos comparados. Assim, nesses casos, foi conduzido o teste não paramétrico de MannWhitney (FIELD, 2009). Para os outros casos, foram realizadas análises multivariadas de variância (Manova) para detectar eventuais diferenças. Após as Manovas, o estudo foi complementado por Anovas separadas por variável dependente. A Tabela 1 apresenta os resultados encontrados.

Tabela 1 | Comparações entre trabalhadores e colegas (pares)

\begin{tabular}{|c|c|c|c|c|c|c|c|}
\hline & & & Média & DP & $\begin{array}{c}\text { IC } \\
(95 \%)\end{array}$ & $\begin{array}{l}\text { Estatísticaa } \\
\qquad(g /)\end{array}$ & $p$ \\
\hline \multirow{9}{*}{$\begin{array}{l}\text { Dimen- } \\
\text { sões de } \\
\text { contexto }\end{array}$} & \multirow{3}{*}{$\begin{array}{l}\text { Condições de } \\
\text { trabalho }\end{array}$} & Geral & 8,85 & 1,45 & & $U=2.118 .000$ & $<0,001$ \\
\hline & & Telet. & 9,59 & 1,09 & {$[9,21-9,79]$} & & \\
\hline & & Coleg. & 8,23 & 1,44 & {$[7,88-8,57]$} & & \\
\hline & \multirow{3}{*}{$\begin{array}{l}\text { Organização do } \\
\text { trabalho }\end{array}$} & Geral & 6,89 & 1,84 & & $F(1,100)=7,811$ & $<0,001$ \\
\hline & & Telet. & 7,44 & 1,54 & {$[6,92-7,97]$} & & \\
\hline & & Coleg. & 6,38 & 1,96 & {$[5,91-6,85]$} & & \\
\hline & \multirow{3}{*}{$\begin{array}{c}\text { Relações de } \\
\text { trabalho }\end{array}$} & Geral & 8,38 & 1,48 & & $F(1,100)=3,921$ & $<0,05$ \\
\hline & & Telet. & 8,71 & 1,47 & {$[8,279,14]$} & & \\
\hline & & Coleg. & 8,09 & 1,46 & {$[7,70-8,48]$} & & \\
\hline
\end{tabular}




\begin{tabular}{|c|c|c|c|c|c|c|c|}
\hline & & & Média & DP & $\begin{array}{c}\text { IC } \\
(95 \%)\end{array}$ & $\begin{array}{l}\text { Estatística } \\
\qquad(g /)\end{array}$ & $p$ \\
\hline \multirow{12}{*}{$\begin{array}{l}\text { Dimen- } \\
\text { sões de } \\
\text { desem- } \\
\text { penho }\end{array}$} & \multirow{3}{*}{ Regulação } & Geral & 9,06 & 0,944 & & $U=1.862 .500$ & $<0,001$ \\
\hline & & Telet. & 9,42 & 0,83 & {$[9,16-9,68]$} & & \\
\hline & & Coleg. & 8,75 & 0,93 & {$[8,51-8,99]$} & & \\
\hline & \multirow{3}{*}{ Esforço } & Geral & 7,44 & 1,43 & & $F(1,100)=3,980$ & $<0,05$ \\
\hline & & Telet. & 7,75 & 1,30 & {$[7,34-8,16]$} & & \\
\hline & & Coleg. & 7,25 & 1,50 & {$[6,88-7,62]$} & & \\
\hline & \multirow{3}{*}{$\begin{array}{c}\text { Execução/ } \\
\text { Monitoramento }\end{array}$} & Geral & 8,24 & 1,52 & & $F(1,100)=15,10$ & $<0,001$ \\
\hline & & Telet. & 8,86 & 1,22 & {$[8,45-9,26]$} & & \\
\hline & & Coleg. & 7,83 & 1,52 & {$[7,46-8,19]$} & & \\
\hline & \multirow{3}{*}{$\begin{array}{l}\text { Autogerencia- } \\
\text { mento }\end{array}$} & Geral & 8,96 & 1,06 & & $F(1,100)=17,727$ & $<0,001$ \\
\hline & & Telet. & 9,42 & 0,90 & {$[9,13-9,71]$} & & \\
\hline & & Coleg. & 8,61 & 1,04 & {$[8,34-8,87]$} & & \\
\hline \multirow{6}{*}{$\begin{array}{l}\text { Dimen- } \\
\text { sões de } \\
\text { afeto }\end{array}$} & \multirow{3}{*}{ Afeto positivo } & Geral & 7,04 & 2,34 & & $F(1,100)=15,946$ & $<0,001$ \\
\hline & & Telet. & 8,00 & 1,92 & {$[7,36-8,64]$} & & \\
\hline & & Coleg. & 6,16 & 2,33 & {$[5,61-6,77]$} & & \\
\hline & \multirow{3}{*}{ Afeto negativo } & Geral & 3,04 & 2,06 & & $U=568,00$ & $<0,001$ \\
\hline & & Telet. & 2,01 & 1,20 & {$[1,46-2,56]$} & & \\
\hline & & Coleg. & 3,88 & 2,24 & {$[3,38-4,37]$} & & \\
\hline
\end{tabular}

Fonte: elaborado pelas autoras.

Os resultados revelam que houve diferenças significativas entre teletrabalhadores e colegas para todas as variáveis abordadas: contexto de trabalho, bem-estar e desempenho profissional. As percepções dos teletrabalhadores foram mais positivas que as percepções dos colegas não teletrabalhadores para todas as variáveis pesquisadas.

Quando comparados com colegas que possuem os mesmos cargos e desenvolvem as mesmas atividades, os teletrabalhadores apresentam desempenho profissional e bem-estar no trabalho mais elevados, além de avaliações mais positivas das relações socioprofissionais, condições e organização do trabalho. Esses resultados sustentam achados e teorias de estudos anteriores sobre os benefícios do teletrabalho (ADERALDO, I. L.; Aderaldo, C. V. L.; lima ，2017; Belzunegui; Erro; Pastor, 2014; Caillier, 2013; TAHAVORI, 2014). Assim, no Serpro, o teletrabalho está associado a melhores avaliações de contexto, de bem-estar e de desempenho.

Como explicar essas diferenças? O arranjo de teletrabalho modifica aspectos importantes da organização do trabalho. Espera-se uma maior autonomia e controle do próprio executor sobre suas tarefas, com um monitoramento menos acirrado e foco na 
entrega de resultados (ADERALDO; ADERALDO; LIMA, 2017; GROEN et al., 2018; KonRADT; SCHMOOK; MALECKe, 2000; Rosenfield; Alves, 2011). A partir de dados levantados com mais de 20 mil trabalhadores holandeses, Van den Heuvel et al. (2010) constataram que, entre os principais antecedentes do desempenho profissional, está a autonomia no trabalho. No Brasil, Fogaça e Coelho Jr. (2015) verificaram que a autonomia é uma variável de alta importância para variabilidade observada no desempenho profissional, pois quando ela está presente, as decisões podem ser tomadas imediatamente, sem que o funcionário tenha que recorrer a um superior hierárquico. As atividades, portanto, podem ser cumpridas em tempo hábil e os objetivos alcançados mais rapidamente. É possível inferir que justamente essa liberdade, controle e rapidez na organização das tarefas e resolução de problemas, presentes no teletrabalho, afetam positivamente a percepção do teletrabalhador.

Em relação ao bem-estar, variáveis como controle e autonomia são clássicas nos modelos explicativos do fenômeno. Nos estudos sobre estresse, autonomia e controle no trabalho têm assumido um papel central nas respostas funcionais do indivíduo (KARASEK, 1979; SLEMP; KeRN; VeLLA-BODRICK, 2015). Conforme os referidos autores, um alto nível de controle no trabalho protege o indivíduo de efeitos negativos das demandas, já que possibilita a tomada de decisões, a resolução de dificuldades e o enfrentamento de desafios.

Conforme os relatos dos participantes da pesquisa, além dos aspectos da organização do trabalho, entre os pontos positivos apontados pelos respondentes, estão as melhorias nas condições de trabalho, expressas pelo conforto da casa do trabalhador e adequação de aspectos físicos do ambiente. O teletrabalho também afeta questões mais práticas da rotina do empregado, como a possibilidade de evitar o trânsito intenso de grandes cidades, a economia de tempo de deslocamento entre a casa e a organização e de gastos com roupas e alimentação. Essas variáveis afetam diretamente o bem-estar e a qualidade de vida geral.

Sobre as relações socioprofissionais, embora todos os atores organizacionais participantes da pesquisa tenham indicado uma preocupação com a invisibilidade do teletrabalhador, com o isolamento social e com as limitações na comunicação, a possibilidade de trabalhar sem interrupções de colegas e o distanciamento de conflitos comuns ao convívio social nos grupos podem ajudar a explicar a percepção mais positiva por parte dos teletrabalhadores. 
É possível afirmar, portanto, que o teletrabalho envolve apenas benefícios e resultados positivos para os trabalhadores? Embora muitos pontos positivos tenham sido apontados de forma consistente pelos respondentes, ainda há espaço para melhorias. Por exemplo, as dificuldades técnicas representaram grande parte do discurso de chefes e usuários do teletrabalho sobre os pontos negativos do arranjo, indicando que aspectos básicos de infraestrutura tecnológica ainda carecem de aprimoramento. Nesse sentido, conforme as tecnologias de informação e comunicação se desenvolvem, novas necessidades vão surgindo, e atualizações vão sendo demandadas. A organização deve estar preparada e atenta para responder e atendê-las.

Também esteve presente em todos os grupos a percepção de problemas relativos à interação e ao convívio social do teletrabalhador. Trata-se de um desafio que pode ser minimizado com o suporte tecnológico adequado e com práticas como reuniões presenciais ou outros eventos periódicos com teletrabalhadores. Nesse sentido, a cultura organizacional e a própria cultura local podem ajudar a explicar a avaliação negativa quanto ao afastamento físico do teletrabalhador e a importância atribuída pelas pessoas a essa configuração (LEWIS, 2013). O isolamento e o excesso de individualidade são tópicos comumente resgatados em estudos que envolvem novas tecnologias (ANTUNES; BRAGA, 2009) e convidam pesquisadores e gestores a repensarem e discutirem os novos arranjos de trabalho.

Embora seja verificada uma compatibilidade entre as percepções de chefes, colegas e teletrabalhadores, algumas especificidades foram constatadas. Por exemplo, os teletrabalhadores apontam preconceito e resistência por parte de colegas e chefias, o que pode estar relacionado justamente com uma cultura local e organizacional que valoriza as relações e comunicações cara a cara (LEWIS, 2013), mas também com resistências frente a um arranjo e uma forma de organização do trabalho com os quais as pessoas não estão acostumadas. Quando se pensa em contextos de isolamento social trazido por crises e pandemias, como o da Covid-19, o teletrabalho pode passar de alternativa à única opção viável.

As tradicionais formas de organização do trabalho, baseadas, por exemplo, em princípios tayloristas, pressupõem um monitoramento constante e um controle do trabalho a partir da presença física do empregado e do cumprimento de horários na organização 
(Alves, 2011; BARRos; Silva, 2010; FerreirA, 2017). Por outro lado, o teletrabalho exige a superação desses princípios rumo a uma gestão mais autônoma das atividades e a um possível maior equilíbrio entre demandas da vida pessoal e profissional (GROEN, 2018; KIM; LEE, 2020).

As chefias respaldam esse cenário quando apontam os problemas com a preparação e a adaptação dos envolvidos com o teletrabalho. Além disso, destacam a necessidade de adaptação constante da gestão frente à quebra de paradigmas resultante do teletrabalho e outras questões mais formais e normativas da organização, como a impossibilidade de registro de ponto, o que dificulta a gestão da jornada de trabalho do empregado. Diante de vantagens e desafios, toda a organização precisa estar envolvida, informada e preparada para um arranjo como o teletrabalho, uma vez que a cultura organizacional em si precisa ser repensada. Em suma, a participação coletiva de gestores, teletrabalhadores e colegas necessariamente deve ser estimulada para o planejamento e gestão do teletrabalho.

\section{Contribuições, limitações e novos estudos}

O estudo e a compreensão do teletrabalho consistem em um tema cada vez mais relevante no campo da administração, no Brasil e no mundo, vis-à-vis a perspectiva de novas e cada vez mais frequentes pandemias. Nesse sentido, este estudo veio contribuir com as pesquisas de gestão de pessoas, ao lançar luz nos pontos positivos e negativos da implementação do teletrabalho. Ao mesclar métodos qualitativos e quantitativos, realizando a tão propalada triangulação metodológica, o estudo somou também por permitir uma melhor compreensão do fenômeno, para além de sua simples mensuração.

Enquanto implicações práticas, os resultados por ora coligidos compõem um diagnóstico que pode inspirar gestores públicos quando da adoção deste arranjo de trabalho, que traduz uma realidade progressivamente mais possível e necessária nas organizações. Como limitações, pode-se citar o caráter transversal do estudo, o qual permitiu retratar um panorama pontual do teletrabalho no Serpro, o que impossibilita quaisquer inferências de relações causais ou de generalização dos resultados. 
Nesse sentido, novas pesquisas podem coletar dados em diferentes momentos para que o tema possa ser analisado em caráter longitudinal, em base contínua. Ademais, estudos futuros também podem comparar os achados do contexto do Serpro com aqueles de outras organizações. Outros tipos de indicadores para comparação dos grupos, como indicadores objetivos de desempenho profissional, devem ser considerados no delineamento das pesquisas. Aspectos mais formais e normativos dos modelos de gestão adotados pelas organizações também podem ser incluídos na discussão do tema. Os autores ressaltam que as opiniões expressas neste texto refletem exclusivamente o entendimento dos autores e não correspondem, necessariamente, à posição do Serpro sobre os assuntos tratados.

\section{Considerações finais}

Embora o teletrabalho seja uma forma de organização do trabalho com algumas décadas de existência no mercado, ainda se trata de um arranjo pouco discutido e utilizado pelas organizações brasileiras, especialmente no setor público. Dessa forma, espera-se que o presente estudo contribua para encorajar e sustentar a discussão de pesquisadores e gestores sobre a implantação do teletrabalho nas organizações brasileiras, independente do setor em que estejam inseridas, oferecendo pistas e perspectivas sobre benefícios, desafios e possibilidades.

Se, por um lado, a literatura aponta aspectos negativos de arranjos como o teletrabalho, os resultados encontrados sustentam a relação positiva do teletrabalho com a percepção do contexto, o bem-estar e o desempenho dos empregados. Foi possível oferecer um retrato do arranjo na organização investigada a partir da ótica de diferentes atores organizacionais.

É possível afirmar que, depois de vários anos de experiência com o arranjo, seu funcionamento está perfeito? Os achados indicam que não. Por outro lado, muitas são as vantagens verificadas. Os pontos negativos podem ser compreendidos como desafios a serem superados. As demandas e necessidades dos grupos de trabalho e da organização vão se modificando ao longo do tempo e os desafios, portanto, vão se transformando. Por 
conseguinte, novas formas de organização e de relações de trabalho devem estar sempre presentes nas pautas dos gestores.

\section{Referências}

Aderaldo, I. L.; Aderaldo, C. V. L.; Lima, A. C. Aspectos críticos do teletrabalho em uma companhia multinacional. Cadernos EBAPE.BR, v. 15, n. spe, p. 511-533, set. 2017.

AgAPITO, P. R.; FiLho, A. P.; SiQUeIRA, M. M. Bem-estar no trabalho e percepção de sucesso na carreira como antecedentes de intenção de rotatividade. Revista de Administração da Mackenzie, v. 16, n. 3, p. 71-93, nov./dez. 2015.

AndRade, L. L. S.; Oliveira, M. A.; PANTOjA, M. J. Teletrabalho no setor público: uma revisão sistemática da literatura internacional a partir do método Proknow-c. In: CONGRESSo INTERnACIONAL DE DESEMPENHo do SETOR PúBliCo, 3, 2019, Florianópolis, Anais... Florianópolis, 2019. Disponível em: htp://www.cidesp.com.br/inde..php/Icidesp/2cidesp/paper/view/881. Acesso em: 5 setembro 2019.

ALVES, G. Trabalho e subjetividade: o espírito do Toyotismo na era do capitalismo manipulatório. São Paulo: Boitempo, 2011.

ANTUNES, R.; BRAGA, R. Infoproletários: degradação real do trabalho virtual. São Paulo: Boitempo, 2009.

Barros, A. M.; SilvA, J. R. G. Percepções dos indivíduos sobre as consequências do teletrabalho na configuração home-office: estudo de caso na Shell Brasil. Cadernos EBAPE.BR, v. 8, n. 1, p. 71-91, mar. 2010.

Belzunegui, A.; ERRo, A.; PASTOR, I. The telework as an organizational innovation in the entities of the third sector. Journal of Electronic Commerce in Organizations, v. 12, n. 1, p. 1-15, jan./mar. 2014.

CAILLIER, J. G. Are teleworkers less likely to report leave intentions in the United States Federal Government than non-teleworkers are? The American Review of Public Administration, v. 45, n. 1, p. 72-88, jan. 2013.

CALVo, R. et al. Happily ever after? Pre-and-post disaster determinants of happiness among survivors of hurricane Katrina. Journal of Happiness Studies, v. 16, n. 2, p. 427-442, mar. 2015.

CARNEVAlE J. B.; HATAK I. Employee adjustment and well-being in the era of COVID-19: i mplications for human resource management. Journal of Business Research, v. 116, p. 183-187, ago. 2020.

CAMARGO, B. V.; JUSTO, A. M. Iramuteq: um software gratuito para análise de dados textuais. 
Temas em Psicologia, v. 21, n. 2, p. 513-518, dez. 2013.

CAPPELLI, P. Rethinking employment. British Journal of Industrial Relations, v. 33, n. 4, p. 563-602, dez. 1995.

COELHo JR., F. A.; Borges-ANDRADE, J. E. Efeitos de variáveis individuais e contextuais sobre desempenho individual no trabalho. Estudos de Psicologia, v. 16, n. 2, p. 111-120, mai./ago. 2011.

COELHo JR., F. A. et al. Validação psicométrica de medida de auto-avaliação de desempenho no trabalho. In: ENCONTRo ANUAL D A AsSOCIAÇÃo NACIONAL D OS PROgRAmas D E PósGradução E M AdMINISTRAÇÃo, 34., 2010, Rio de Janeiro. Anais... Rio de Janeiro: Anpad, 2010.

CUnhA, M. P.; Rego, A.; LOPES, M. P. Comportamento organizacional positivo. Análise Psicológica, v. 4, n. 31, p. 313-328, dez. 2013.

DEMO, G.; PASCHOAL, T. Well-being at work scale: exploratory and confirmatory validation in the USA. Paidéia, Ribeirão Preto ， v. 26, n. 63, p. 35-43, jan./abr. 2016.

DEMO, G.; PESSÔA, R. CRM na administração pública: desenvolvimento e validação de uma e scala de $r$ elacionamento com o c idadão (ERCi). Revista de Administração Pública, v. 49, n. 3, p. 677-697, mai./jun. 2015.

DONNELLY, R.; JOHNS, J. Recontextualising remote working and its HRM in the digital economy: an integrated framework for theory and practice. The International Journal of Human Resource Management, v. 31, p. 1-23, mar. 2020.

FERREIRA, M. C. Qualidade de vida no trabalho: uma abordagem centrada no olhar dos trabalhadores. Brasília, DF: Paralelo 15, 2017.

FIELD, A. Discovering statistics using SPSS. Thousand Oaks, CA: Sage, 2009.

FILARDI, F.; CASTRO, R. M.; ZANINI, M. T. F. Vantagens e desvantagens do teletrabalho na administração pública: análise das experiências do Serpro e da Receita Federal. Cadernos EBAPE. $B R$, v. 18, n. 1, p. 28-46, jan./mar. 2020.

FogaçA, N.; Coelho JR., F. A. A hipótese "trabalhador feliz, produtivo": o que pensam os servidores públicos federais. Cadernos EBAPE.BR, v. 13, n. 4, p. 759-775, out./dez. 2015.

GRANT, A. M.; PARKER, S. K. Redesigning work design theories: the rise of relational and proactive perspectives. Academy of Management Annals, v. 3, n. 1, p. 317-375, jul. 2009.

GRANT, C. A.; WAllace, L. M.; SPURGeon, P. C. An exploration of the psychological factors affecting remote e-worker's job effectiveness, well-being and work-life balance. Employee Relations, Cidade, v. 35, n. 5, p. 527-546, 2013.

GROEN, B. A. C. et al. Managing flexible work arrangements: teleworking and output controls. European Management Journal, v. 36, n. 6, p. 727-735, 2018.

KARASEK, R. A. Job demands, job decision latitude, and mental strain: implications for job redesign. Administrative Science Quarterly, v. 24, n. 2, p. 285-308, jun. 1979. 
KIM, S. Y.; LEE, D. Work-life program participation and employee work attitudes: aquasiexperimental analysis using matching methods. Review of Public Personnel Administration, v. 40, n. 3 , p. $468-490$, set. 2020

KONRADT, U.; SCHMOOK, R.; MALECKE, M. Impacts of telework on individuals, organizations and families: a critical review. International Review of Industrial and Organizational Psychology, v. 15, p. 63-99, 2000.

LEWIS, R. A. The influence of information technology on telework: the experiences of teleworkers and their non-teleworking colleagues in a French Public Administration. Journal of Information and Education Technology, v. 3, n. 1, p. 32-35, fev. 2013.

Neiva, E. R.; Macambira, M. O.; Ribeiro, E. B. A. Práticas de gestão, bem-estar e comportamento de apoio. RAM. Revista de Administração Mackenzie, v. 21, n. 1, p. 1-27, fev. 2020.

MAgALhÃES, H. Fique em casa com o P rojeto Lar. Tema, 1, p. 23-24, 1985.

MASSIMO, N. Smart working: una prospettiva critica. Bologna: TAO Digital Library, 2017.

OliVEIRA, M. Z. et al. Performance, satisfaction and intention to remain in organizations: individual to contextual predictors. Trends in Psychology, v. 27, n. 2, p. 549-567 , 2019.

PASchoal, T.; TAMAYO, A. Construção e validação da escala de bem-estar no trabalho. Avaliação Psicológica, v. 7, n. 1, p. 11-22, 2008.

PASChOAL, T; Alvaro, J. L.; PORTO, J. The moderating effect of personal values in the relationship between working conditions and wellbeing. International Journal of Social Psychology, v. 30, n. 1, p. 89-121, jan. 2015.

PETERS, P. et al. Enjoying new ways to work: an HRM-process approach to study flow. Human Resource Management, v. 53, n. 2, p. 271-290, mar. 2014.

RoCHA, C. T. M.; AMADOR, F. S. O teletrabalho: conceituação e questões para análise. Cadernos EBAPE.BR, v. 16, n. 1, p. 152-162, jan. 2018.

Rosenfield, C. L.; Alves, D. A. Teletrabalho. In: Cattani, A. D.; Holzmann, L. (Ed.). Dicionário de trabalho e tecnologia. Porto Alegre: Zouk, 2011. p. 414-418.

SEEJEEN, P.; CHO, J. C. Does telework status affect the behavior and perception of supervisors? Examining task behavior and perception in the telework context. The International Journal of Human Resource Management, v. 31, p. 1-26, 2020.

SILVA, E. S. Trabalho e desgaste mental: o direito de ser dono de si mesmo. São Paulo: Cortez, 2011.

SLEMP, G., KERN, M.; VeLLA-BRODRICK, D. Workplace well-being: the role of job crafting and autonomy support. Psychology of Well-Being, v. 5, n. 1, p. 1-17, ago. 2015.

Sociedade Brasileira d e Teletrabalho e Teleatividades (Sobratt). Pesquisa Home Office. 2018. Disponível em: <https://drive.google.com/file/d/1Lh0az_BIX6j-GS_KXkbAvAQyl2z5U-bc/ view> Acesso em: 08 agosto 2020. 
TAHAVORI, Z. Teleworking in the National Library and Archives of Iran: teleworkers' atitudes. Journal of Librarianship and Information Science, v. 47, n. 4, p. 1-15, mai. 2014.

VAn Den Heuvel, S. G. et al. Productivity loss at work; health-related and work-related factors. Journal of Occupational Rehability, v. 20, n. 3, p. 331-339, set. 2010.

VREULS, E. H.; JOIA, L. A. Proposição de um modelo exploratório dos fatores relevantes para o desempenho profissional do CIO brasileiro. Revista de Administração, v. 47, n. 2, p. 307-324, abr./ mai./jun. 2012.

WARR, P. Work, happiness and unhappiness. New Jersey: Lawrence Erlbaum Associates, 2007.

\section{Karina Pereira Bastos Vilarinho}

(iD) https://orcid.org/ 0000-0003-1872-961X

Bacharel em Administração de Empresas pelo Centro de Ensino Unificado de Brasília. Especialização em Gestão Pública com Ênfase em Estratégia na Universidade de Brasília - UnB.

E-mail: karina.villarinho@gmail.com

\section{Tatiane Paschoal}

(iD) https://orcid.org/ 0000-0002-2688-1411

Doutora em Psicologia Social, do Trabalho e das Organizações. Professora Adjunta do Departamento de Administração da Universidade de Brasília.

E-mail: paschoal@unb.br

\section{Gisela Demo}

(iD) https://orcid.org/ 0000-0003-1864-0471

Doutora em Psicologia Organizacional (UnB) e pós-doutora em Management (UCLA/USA). Professora e pesquisadora do PPGA/UnB, bolsista do CNPq, líder de grupo de pesquisa e editora associada da Revista Brasileira de Gestão de Negócios. E-mail: giselademo@unb.br 